\title{
Sequestration and the Engagement of Developing Economies in a Global Carbon Market
}

\author{
Reza Oladi* \\ Department of Applied Economics \\ Utah State University
}

\author{
Arthur J. Caplan \\ Department of Applied Economics \\ Utah State University
}

\author{
John Gilbert \\ Department of Economics and Finance \\ Utah State University
}

\begin{abstract}
We develop a differential game within a general equilibrium framework of carbon sequestration with and without international trade. We characterize the game's equilibrium and demonstrate how a global carbon permit market can be structured to induce the participation of developing countries through the harnessing of their potential to sequester carbon. We show that a permit market with carbon sequestration is mutually welfare improving for developed and developing nations, and that international trade in finished goods and carbon permits lowers the stock of global pollution.
\end{abstract}

JEL: F1, Q2, C6

Keywords: Environment and trade, sequestration, carbon permits, differential games

\footnotetext{
${ }^{*}$ We are grateful to two anonymous referees as well as the editor of this journal for their insightful suggestions and comments. Address correspondence to Reza Oladi, Department of Applied Economics, Utah State University, 4835 Old Main Hill, Logan UT 84322-4835. Ph: 435-797-8196. Fax 435-797-0402. E-mail reza.oladi@usu.edu.
} 


\title{
Sequestration and the Engagement of Developing Economies in a Global Carbon Market
}

\begin{abstract}
We develop a differential game within a general equilibrium framework of carbon sequestration with and without international trade. We characterize the game's equilibrium and demonstrate how a global carbon permit market can be structured to induce the participation of developing countries through the harnessing of their potential to sequester carbon. We show that a permit market with carbon sequestration is mutually welfare improving for developed and developing nations, and that international trade in finished goods and carbon permits lowers the stock of global pollution.
\end{abstract}

$J E L: \mathrm{F} 1, \mathrm{Q} 2, \mathrm{C} 6$

Keywords: Environment and trade, sequestration, carbon permits, differential games

\section{Introduction}

It is widely accepted among climate scientists that human-induced climate change is occurring. Yet the debate over what, if anything, should be done about the problem continues on multiple fronts. The debate is underscored by the question of how society should balance the (certain) economic costs associated with containing the problem today with the (uncertain) socioeconomic benefits obtained in the future (Hansen, et al., 2006; Nordhaus, 2007; Stern, 2007). Nordhaus (2007) argues that an optimal policy (or set of policies) will involve modest rates of emissions reductions in the near term, followed by sharp reductions in the medium and long terms. He calls this approach the "climate-policy ramp," in which policies to slow climate change increasingly tighten over time. To the contrary, the Stern 
Review (2007) and Gore (2007) propose drastically lower discount rates than those used in the Nordhaus (2007) study, which in turn magnify climate-change impacts in the distant future and sanction deeper cuts in emissions today. ${ }^{1}$

It is also unclear which policies might be the most effective in controlling carbon emissions. The practicality of taxes versus permits (Pizer, 1997; Kaplow, 2010), adoption of cleaner technologies, and, of particular interest in the context of this paper, the potential for carbon sequestration in soils and forests continue to be assessed (USGS, 2011; Feng et al., 2004). Further, while developing-nation participation in the global control effort is generally considered to be a necessary condition for successful mitigation of climate change, there is also continued debate over the extent to which developing nations should be required to participate in this effort (Rose et al., 1998; Cooper, 1998). And there is noticeable reticence on the part of some developed and developing nations concerning their perceived roles in any future global agreement (Batabyal, 1997 and 2000; Benchekroun and Long 2012; Long 2015).

This paper contributes to the debate by investigating the joint role carbon sequestration and international permit trading might play in inducing developing (henceforth Southern) nations to participate in a global effort to mitigate climate change. Our objective is to demonstrate exactly how international trade in carbon permits can induce the participation of Southern nations by harnessing their potential to sequester carbon in a manner that enhances not only their welfare, but also that of the developed (henceforth Northern) nations (see also Benitez et al., 2007, and Sohngen and Sedjo, 2004). At the outset, we note that this paper does not address other carbon reduction strategies such as subsidized adoption of clean technology or implementation of a carbon tax. Rather, we address the question of whether,

\footnotetext{
${ }^{1}$ Nordhaus' (2007) Dynamic Integrated model of Climate and the Economy (DICE) proposes an optimal policy that would first reduce global carbon emissions by 15 percent in the initial years, increasing to 25 percent by 2050 , and 45 percent by 2100 . This translates into a global temperature rise relative to the year 1900 of $2.8^{\circ} \mathrm{C}$ by 2100 and $3.4^{\circ} \mathrm{C}$ in 2200 , with corresponding global abatement costs of $\$ 2.2$ trillion (and global net benefit of roughly $\$ 1.2$ trillion). In contrast, the Gore (2007) and Stern Review (2007) studies call for emissions reductions of 85-90 percent below current levels by 2050. Based on the DICE model, this translates into global net costs of $\$ 17$ trillion to $\$ 22$ trillion relative to no controls.
} 
and under what circumstances, a dynamic comparative advantage in carbon sequestration alone provides a strong-enough incentive for Southern nations to join in a global permit market with Northern nations, where the possibility exists for the South to export carbon permits to the North in exchange for imported finished goods. ${ }^{2}$

There is in fact considerable evidence to suggest that Southern nations enjoy a comparative advantage in carbon sequestration. For instance, Conant (2010) and Keane et al. (2010) discusses how Southern nations' comparative advantage in sequestration arises through grasslands management and cleaner production in agricultural products, respectively. Benitez et al. (2007) estimate global sequestration supply curves for afforestation and reforestation activities based on highly disaggregated (grid-level) physical data with country-level controls for political, financial, and economic risks. They find that low-cost sequestration sites are located mainly in Southern regions, such as Sub-Saharan Africa, Southeastern Brazil, and Southeast Asia.

Our main theoretical innovation in this paper is the development of a dynamic game in a general-equilibrium context of carbon sequestration in conjunction with international trade in carbon permits and finished goods. We consider a two-region world (North vs. South) in which labor in each region may be used to produce a composite finished good for consumption that emits carbon as a by-product, or may instead be used for carbon sequestration. We make a distinction between the flow of carbon emissions and the global carbon stock. The latter is assumed to affect economic welfare in each region. In the context of a differential game between the North and South, we characterize the properties of a

\footnotetext{
${ }^{2}$ Myriad differences across nations can drive comparative advantages associated with carbon sequestration. For example, differences in monitoring and enforcement capability across nations can easily distort an equilibrium carbon price that would otherwise accurately reflect extant comparative advantages in the production of carbon sequestration and finished goods. Distortions wrought by existing region-specific regulations placed on localized pollutants, or localized non-convexities associated with damages incurred via the global carbon stock itself (e.g., uncertain tipping points in regional damage functions), could similarly detract from a region's welfare gains otherwise obtained through exploitation of its respective comparative advantage in sequestration or production of finished goods. Incorporating these additional types of heterogeneity in our model would complicate the analysis and cloud our understanding of the extent to which joint implementation of carbon sequestration and permit trading can lead to mutual welfare gains in the context of a basic international trade model.
} 
corresponding Nash equilibrium, both in terms of the carbon stock's time path and its steadystate level. We derive the conditions under which the South has a dynamic comparative advantage in carbon sequestration. We show that an international permit market coupled with carbon sequestration is mutually welfare improving, and that international trade in the finished good and carbon permits lowers the global stock of carbon.

Although our results are founded upon relatively complex dynamic analyses, our main message is both simple and compelling. The South retains an incentive to participate in a global permit market given its comparative advantage in carbon sequestration. Thus, enlistment of developing nations in a global effort to control climate change relies at least in part on substantiating the merits of carbon sequestration in conjunction with a global permit market. This paper rigorously characterizes the merits associated with joint implementation of these two control mechanisms.

In this sense, our paper is related to branches of literature dealing with international environmental agreements, e.g., Caplan et al. (2003), which considers the role of carbon trading in an efficient equilibrium within the context of a United Nations' protocol, De Zeeuw (2008), which studies the optimal size of such agreements, and Pavlova and De Zeeuw (2013), which incorporates national asymmetries in environmental benefits and damages. The paer is also related to Porter (1990) and Porter and van der Linde (1995), which consider the effects of environmental regulation on technological change and the dynamics of competition. Further, Acemoglu et al. (2012) show that technical progress directed toward a clean intermediate good sector is optimal in terms of long-term growth in the presence of optimal environmental regulation (see also Hemous, 2016, and Bijgaart, 2017).

The paper is organized as follows. In Section 2 we set out a basic dynamic model of production and emissions under autarky. Section 3 then extends the analysis to allow for the possibility of carbon sequestration. Section 4 further extends the model to allow for international trade. Concluding comments are provided in Section 5. 


\section{A Basic Model of Emissions and Production}

To begin we develop a simple dynamic model of an autarkic global economy in the absence of carbon sequestration. We assume a Ricardian Northern region (region 1) and Southern region (region 2), each with their own production sectors, where the respective fully-employed labor forces are constant proportions of constant populations. The regional production functions are given by:

$$
Y_{j}(t)=\alpha_{j} L_{j}^{Y}(t) \quad j=1,2
$$

where $Y_{j}$ and $L_{j}^{Y}$ are production and production-sector employment levels, respectively, in period $t$ and region $j$, and the $\alpha_{j}>0$ are respective productivity constants. Each region's production results in carbon emissions as a by-product. For simplicity, assume that region j's emissions per unit of output are fixed, i.e:

$$
e_{j}(t)=\frac{Y_{j}(t)}{\beta_{j}} \quad j=1,2
$$

where the $e_{j}>0$ are period $t$ emission levels and the $\beta_{j}>0$ are emissions-productivity constants. $^{3}$

Let $W_{j}$ denote region $j$ 's welfare level, which takes the form:

$$
W_{j}(t)=u_{j}\left(C_{j}(t)\right)-f_{j}(E(t)) \quad j=1,2
$$

where $C_{j}$, and $E$ are region $j$ 's aggregate consumption level and the global carbon stock at time $t$, respectively. The first term in region $j$ 's welfare function represents utility obtained

\footnotetext{
${ }^{3}$ This Ricardian production function is equivalent to a Leontief production function $Y(t)=$ $\min \left\{\alpha L_{Y}(t), \beta e(t)\right\}$ (see Beladi and Oladi, 2011, and Beladi et al., 2013). As alluded to in Section 1, this type of simplifying technology assumption, along with those to follow concerning the carbon stock's constant rate of decay and deterministic regional sequestration productivities and damages associated with the carbon stock, enable us to retain a focus on the role of carbon sequestration in the determination of a trading equilibrium. Interestingly, potential problems associated with asymmetric information across regions are effectively muted in this model due to the endogeneity of the regional permit-allocation mechanisms and free trade in both the carbon and finished-good sectors, as well as the assumption of two regions.
} 
via consumption of the finished good, while the second term represents aggregate economic damage associated with the global stock of carbon. ${ }^{4}$ Both $u_{j}$ and $f_{j}$ are continuous and twice differentiable. We also assume that $u_{j}^{\prime}()>$.0 and $u_{j}^{\prime \prime}() \leq 0,. \forall C_{j}>0, f_{j}^{\prime}()>$. and $f_{j}^{\prime \prime}()>0,. \forall E>0$, and $\lim _{E \rightarrow \infty} f_{j}^{\prime}(E)=\infty$. Except where necessary, we henceforth suppress time indicator $t$ for notational simplicity. The global carbon stock evolves through time according to:

$$
\dot{E}=\sum_{j=1}^{2} e_{j}-\sigma E
$$

where $\sigma$ is a constant natural rate of decay (i.e, atmospheric assimilation) of the global carbon stock.

Let $\bar{L}_{j}$ represent region $j$ 's constant labor supply. Thus, given full employment in each region we have $Y_{j}=\alpha_{j} \bar{L}_{j}$. It follows from equation (2) that $e_{j}=\alpha_{j} \bar{L}_{j} / \beta_{j}$ in each period. Thus, the steady-state, equilibrium global carbon stock is given by:

$$
E^{s s}=\frac{\sum_{j=1}^{2} e_{j}}{\sigma}=\frac{\sum_{j=1}^{2} \frac{\alpha_{j}}{\beta_{j}} \bar{L}_{j}}{\sigma} .
$$

At an autarky equilibrium we have $C_{j}=Y_{j}$, implying that region $j$ 's steady-state welfare level is given by $W_{j}^{s s}=u_{j}\left(\alpha_{j} \bar{L}_{j}\right)-f_{j}\left(\sum_{i=1}^{2} \frac{\alpha_{i}}{\beta_{i}} \bar{L}_{i} / \sigma\right) .^{5}$

\section{Carbon Sequestration Under Autarky}

Our next task is to extend the simple autarky model to incorporate the possibility of carbon sequestration in each region. We maintain that the regional economies are closed in this section, an assumption that is relaxed in due course. Let region $j$ 's sequestration production

\footnotetext{
${ }^{4} \mathrm{As}$ is common in the literature, we assume separability of utility from consumption and disutility from the carbon stock for purposes of tractability.

${ }^{5}$ Given the carbon stock's initial level, $E(0)$, we can readily determine the stock's time path by solving the differential equation (4): $E=\left[\Sigma_{j=1}^{2} \alpha_{j} \bar{L}_{j} / \beta_{j}\right] / \sigma+A \exp [-\sigma t]$ where $A=E(0)-\left[\Sigma_{j=1}^{2} \alpha_{j} \bar{L}_{j} / \beta_{j}\right] / \sigma$. It then follows that in general $W_{j}=u_{j}\left(\alpha_{j} \bar{L}_{j}\right)-f_{j}\left(\left[\Sigma_{j=1}^{2} \alpha_{j} \bar{L}_{j} / \beta_{j}\right] / \sigma+A \exp [-\sigma t]\right)$.
} 
function be given by:

$$
S_{j}=S_{j}\left(L_{j}^{S}\right) \quad j=1,2
$$

where $S_{j}$ and $L_{j}^{S}$ are the levels of carbon sequestration and labor employed in sequestration by region $j$ 's government, respectively, i.e., we assume carbon sequestration is a public sector activity. We further assume that $S_{j}$ is continuous, with $S_{j}(0)=0, S_{j}^{\prime}()>$.0 , and $S_{j}^{\prime \prime}()<$.0 . Note that in contrast with the finished good sector, sequestration technology is not necessarily Ricardian. There is an implicit unpaid fixed factor in addition to labor (e.g., a rainforest) used in the production of carbon sequestration that engenders diminishing returns. Regional divergence in sequestration's marginal product of labor can arise in three different ways - via the endowment of the fixed factor, the technology itself, or the allocation of labor to managing the fixed resource. Function $S_{j}($.$) meets the Inada condition if \lim _{L_{S} \rightarrow 0} S^{\prime}\left(L_{S}\right)=\infty .{ }^{6}$ The law of motion for the global carbon stock is accordingly modified as:

$$
\dot{E}=\sum_{j=1}^{2} e_{j}-\sum_{j=1}^{2} S_{j}\left(L_{j}^{S}\right)-\sigma E .
$$

Consistent with our earlier characterization of welfare, we further assume that region $j$ 's government sells emission permits to its production sector at zero profit, i.e.,

$$
w_{j} L_{j}^{S}=i_{j} e_{j} \quad j=1,2
$$

where $w_{j}$ and $i_{j}$ are the equilibrium wage rate and permit price, respectively, in region $j$. As a public sector, the profit motive need not apply.

The full-employment condition in each region is given by:

$$
L_{j}^{Y}+L_{j}^{S}=\bar{L}_{j} \quad j=1,2
$$

\footnotetext{
${ }^{6}$ We require this condition to subsequently guarantee the existence of a steady-state equilibrium.
} 
and market clearing in the finished good market can be written as:

$$
C_{j}=\alpha_{j}\left[\bar{L}_{j}-L_{j}^{S}\right] \quad j=1,2
$$

The control variables for regional government $j$ 's problem are $L_{j}^{S}$ and $e_{j}$. Substituting out $e_{j}$, the problem for region $j=1,2$ reduces to: ${ }^{7}$

$$
\begin{array}{r}
\max _{L_{j}^{S}} \int_{0}^{\infty}\left[u_{j}\left(\alpha_{j}\left[\bar{L}_{j}-L_{j}^{S}\right]\right)-f_{j}(E)\right] \exp [-r t] d t \\
\text { s.t. } \quad \dot{E}=\sum_{j=1}^{2}\left(\alpha_{j} / \beta_{j}\right)\left[\bar{L}_{j}-L_{j}^{S}\right]-\sum_{j=1}^{2} S_{j}\left(L_{j}^{S}\right)-\sigma E \\
E(0) \geq 0 .
\end{array}
$$

The problem's corresponding current-value Hamiltonian is given by:

$$
H_{j}=\left[u_{j}\left(\alpha_{j}\left[\bar{L}_{j}-L_{S}\right]\right)-f_{j}(E)\right]+\lambda_{j}\left[\left(\alpha_{j} / \beta_{j}\right) \sum_{j=1}^{2}\left[\bar{L}_{j}-L_{j}^{S}\right]-\sum_{j=1}^{2} S_{j}\left(L_{j}^{S}\right)-\sigma E\right]
$$

To both simplify our analysis and for the sake of mathematical tractability we henceforth assume $u_{1}()=.u_{2}()=.u(),. f_{1}()=.f_{2}()=.f(),. \alpha_{1}=\alpha_{2}=\alpha, \beta_{1}=\beta_{2}=\beta$ and $\bar{L}_{1}=\bar{L}_{2}=\bar{L}$. These conditions also permit us to focus attention on the role of carbon sequestration in our model; a role that is motivated by differences between the North's and South's sequestration production functions. First-order conditions corresponding to (14) can therefore be written as:

$$
\begin{array}{r}
\alpha u^{\prime}(.)+\lambda_{j}\left[\frac{\alpha}{\beta}+S_{j}^{\prime}\left(L_{j}^{S}\right)\right]=0 \\
\dot{\lambda}_{j}=f^{\prime}(E)+\lambda_{j}[\sigma+r]
\end{array}
$$

along with equations (12) and (13) and transversality condition $\lim _{t \rightarrow \infty} \lambda_{j} E=0$. For future

\footnotetext{
${ }^{7}$ Since our focus is on carbon sequestration, the scope of strategic interaction between the two regions is limited to sequestration and emission levels. This approach is similar to that employed in Long's (1992) pollution control game.
} 
reference note that (15) implies $\lambda_{j}<0$. Further, total differentiation of (15) results in $\partial L_{j}^{S} / \partial \lambda_{j}<0$

An open-loop Nash equilibrium for the autarky game, denoted $\left(\hat{L}_{1}^{S}(t), \hat{L}_{2}^{S}(t)\right)$, is a solution to the above control problems for regions 1 and $2 .{ }^{8}$ We similarly denote the autarky equilibrium production (consumption) and carbon stock paths as $\hat{Y}_{1}(t), \hat{Y}_{2}(t)$, and $\hat{E}(t)$, respectively. Our next task is to fully characterize these paths, beginning with our first lemma, which is a direct consequence of the previously mentioned simplifying assumptions.

Lemma 1. $\hat{\lambda}_{1}(t)=\hat{\lambda}_{2}(t)$ for all $t$.

Proof. Recall that $\hat{E}(t)$ is our autarky equilibrium path for the global carbon stock (therefore common to both regions). The dynamics of the co-state variables must satisfy (16), which clearly has the same steady-state equilibrium solution for each region. Note also that $\lambda_{j}(0)=$ $\partial w_{j} / \partial E(0)=-f^{\prime}(E(0)), j=1,2$ according to the maximum principle and our interpretation of model's co-state variables.

We now make an explicit assumption concerning the marginal productivities of carbon sequestration. Let us assume that $S_{2}^{\prime}\left(L^{S}\right)>S_{1}^{\prime}\left(L^{S}\right)$ for any $L^{S}>0$. This regional difference could obviously arise because the South has superior sequestration technology, but this is not necessarily what we have in mind. Instead, we assume its larger marginal sequestration productivity arises because the South has a larger endowment of the fixed factor in carbon sequestration (e.g., the rainforest in South America - the lungs of the planet - or a rela-

\footnotetext{
${ }^{8}$ To the extent that sustainability of global environmental agreements in general, and those targeting mitigation of climate change in particular, require relatively strong precommitment (or self-enforcement) among participants, an open-loop equilibrium is the appropriate solution concept for our problem (Fudenberg and Levine, 1988; Fudenberg and Tirole, 1991; Long, 1992, 2010). This is especially the case since both our autarky and trade games are premised on the assumption of self-enforcement to begin with. In the case of the autarky game, the underlying regional Nash equilibria obtained in each period reflect an inherently deterministic, pure strategy space within which the regions essentially ignore the other region's strategies. In the case of the trade game, our framework assumes each region similarly ignores exogenous moves by nature, the possibility of mixed strategies by its rival, and possible deviations by its rival from its equilibrium strategy. The role of self-enforcement in global environmental agreements is addressed in Barrett (1994), which shows that self-enforcement does little to improve upon the Nash outcome when the number of regions that share the resource is large. Caplan et al. (2003) also explore the issue of self-enforcement in the context of the Kyoto Protocol.
} 
tively large, open arable land mass in Africa). This assumption enables us to draw a clear comparison between the North's and South's equilibrium paths.

Proposition 1. Given $S_{2}^{\prime}\left(L^{S}\right)>S_{1}^{\prime}\left(L^{S}\right)$ for any $L^{S}>0$, then at any autarky equilibrium and any time $t$ we have $(i) \hat{L}_{1}^{S}(t)<\hat{L}_{2}^{S}(t)$, which implies $\hat{S}_{1}(t)<\hat{S}_{2}(t)$, and $(i i) \hat{Y}_{1}(t)>\hat{Y}_{2}(t)$.

Proof. It follows from equation (15) and Lemma 1 that:

$$
\frac{u^{\prime}\left(C_{1}(t)\right)}{1 / \beta+\frac{S_{1}^{\prime}\left(L_{1}^{S}(t)\right)}{\alpha}}=\frac{u^{\prime}\left(C_{2}(t)\right)}{1 / \beta+\frac{S_{2}^{\prime}\left(L_{2}^{S}(t)\right)}{\alpha}}
$$

Note that our autarky assumption and market clearing conditions in each region imply $\hat{C}_{j}(t)=\hat{Y}_{j}(t), j=1,2$. It also follows from our setup that $L_{1}^{S}(t)<L_{2}^{S}(t)$ if and only if $Y_{1}(t)>Y_{2}(t)$. Therefore, given market clearing, $L_{1}^{S}(t)<L_{2}^{S}(t)$ if and only if $C_{1}(t)>C_{2}(t)$. To prove our results assume the negation, i.e., at equilibrium $\hat{L}_{1}^{S}(t) \geq \hat{L}_{2}^{S}(t)$, which implies $\hat{C}_{2}(t) \geq \hat{C}_{1}(t)$. This in turn implies $u^{\prime}\left(\hat{C}_{2}(t)\right) \leq u^{\prime}\left(\hat{C}_{1}(t)\right)$. Therefore, for equation (17) to hold we must have $S_{1}^{\prime}\left(\hat{L}_{1}^{S}(t)\right) \geq S_{2}^{\prime}\left(\hat{L}_{2}^{S}(t)\right)$ implying $\hat{L}_{2}^{S}(t) \geq \hat{L}_{1}^{S}(t)$ by our maintained assumption of diminishing marginal productivity (i.e. $S_{j}^{\prime \prime}()<0,. j=1,2$ ), which is a contradiction. Therefore, $\hat{L}_{1}^{S}(t)<\hat{L}_{2}^{S}(t)$, which implies $\hat{S}_{1}(t)<\hat{S}_{2}(t)$ and $\hat{Y}_{1}(t)>\hat{Y}_{2}(t)$.

Proposition 1 shows us that even under autarky regions implicitly capitalize on their respective comparative advantages. In particular, the South produces relatively more carbon sequestration than that produced by what would otherwise be its trading partner in a world with free trade, the North.

Next, we characterize the autarky equilibrium's steady-state. Let $L_{j}^{S}=\phi_{j}(E)$ represent the $L_{j}^{S}-E$ locus along which $\dot{\lambda}_{j}=0$ for $j=1,2$. Similarly, $L_{j}^{S}=\xi_{j}(E), j=1,2$, represents the locus along which $\dot{E}=0$. The following lemma characterizes these two functions:

Lemma 2. (i) $\phi_{j}(E), j=1,2$, is strictly increasing in $E$, and (ii) $\xi_{j}(E), j=1,2$, is strictly decreasing in $E$. 
Proof. Rewrite (15) as:

$$
\lambda_{j}=-\frac{u^{\prime}(.)}{\frac{1}{\beta}+\frac{S_{j}^{\prime}(\cdot)}{\alpha}} .
$$

Substitute (18) into (16) and set $\dot{\lambda}_{j}=0, j=1,2$, to obtain:

$$
f^{\prime}(.)\left[\frac{1}{\beta}+\frac{S_{j}^{\prime}\left(L_{j}^{S}\right)}{\alpha}\right]-(\sigma+r) u^{\prime}(.)=0 \quad j=1,2 .
$$

Totally differentiating (19) with respect to $L_{j}^{S}$ and $E$, applying the previously mentioned curvature conditions on $f(),. S_{j}($.$) , and u($.$) , and rearranging we obtain:$

$$
\phi_{j}^{\prime}(E)=-\frac{\alpha f^{\prime \prime}(.)\left[\frac{1}{\beta}+\frac{S_{j}^{\prime}(.)}{\alpha}\right]}{f^{\prime}(.) S_{j}^{\prime \prime}(.)+\alpha^{2}(\sigma+r) u^{\prime \prime}(.)}>0 \quad j=1,2 .
$$

Similarly, let $\dot{E}=0$ in (12) and totally differentiate with respect to $L_{j}^{S}$ and $E$ to obtain:

$$
\xi_{j}^{\prime}(E)=\frac{-\sigma}{\frac{\alpha}{\beta}+S_{j}^{\prime}(.)}<0 \quad j=1,2 .
$$

We now turn to the existence of a steady-state autarky equilibrium. The following proposition addresses a sufficient condition for the existence of a unique steady-state equilibrium. Local and global stability conditions for this equilibrium are derived in the technical appendix.

Proposition 2. Given the Inada conditions on $S_{j}, j=1,2$, there exists a unique steady-state autarky equilibrium at which the carbon sequestration level for each region is positive.

Proof. Given Lemma 2, in order to establish the existence of a steady-state autarky equilibrium at which each region's sequestration level and the global carbon stock are positive, it suffices to show that $\xi_{j}(0)>\phi_{j}(0), j=1,2$. From equation (19), which implicitly defines $\phi_{j}($.$) ,$ $j=1,2$, we see that $f^{\prime}(E)=\alpha(\sigma+r) u^{\prime}() /.\left[\alpha / \beta+S^{\prime}\left(L_{S}\right)\right]$. Recall that $f^{\prime}(E) \rightarrow 0$ as $E \rightarrow 0$. Thus, it must also be the case that $\alpha(\sigma+r) u^{\prime}\left(\alpha\left[\bar{L}-L_{j}^{S}\right]\right) /\left[\alpha / \beta+S_{j}^{\prime}\left(L_{j}^{S}\right)\right] \rightarrow 0$ as $E \rightarrow 0$. 
Given the Inada conditions on $S_{j}$, this occurs iff $L_{j}^{S} \rightarrow 0$. Therefore, $\lim _{E \rightarrow 0} \phi_{j}(E)=0$, $j=1,2$, since $\phi_{j}$ is monotonically increasing in $E$ by Lemma 1 , implying that $\phi_{j}(E)$ is an injective function. Next, it follows from the definition of $\xi_{j}($.$) ( \dot{E}=0$ via equation 12 ), that $\lim _{E \rightarrow 0}\left[\sum_{j} e_{j}-\sum_{j} S_{j}(\cdot)\right] \rightarrow 0$. Given $e_{j}>0, j=1,2$, this implies $L_{j}^{S}>0, j=1,2$. Since $\xi_{j}$ is monotonically decreasing in $L_{j}^{S}, j=1,2$ from Lemma 1 it is also an injective function. Together these conditions imply that $\xi_{j}(0)>\phi_{j}(0), j=1,2$. Uniqueness of the steady-state autarky equilibrium follows directly from Lemma 2.

The geometry for the autarky steady-state equilibrium is presented in Figure 1, which depicts the equilibrium outcome in terms of sequestration labor levels in both the North and South and the global carbon stock. The equilibrium for region $j=1,2$ is represented by the intersection of functions $\phi_{j}$ and $\xi_{j}$, labeled point(s) $a$.

While we have maintained that both regions have identical labor endowments, it is instructive to consider the effects of a change in the endowment of labor in either of the two regions. The following proposition addresses the effects of such a change in region $j$ 's endowment.

Proposition 3. The autarky equilibrium levels of carbon sequestration and consumption of the finished good in region $j=1,2$ are each positively related to region $j$ 's labor endowment, while the steady-state level of region $k$ 's sequestration (consumption), $k=1,2, k \neq j$, falls (rises). Moreover, the global carbon stock falls with increases in region $j$ 's labor endowment.

Proof. Without loss of generality let $d \bar{L}_{2}>0$ and $d \bar{L}_{1}=0$. By total differentiation of the first-order conditions, we obtain:

$$
\begin{array}{r}
{\left[\frac{\alpha}{\beta}+S_{2}^{\prime}(.)\right] \frac{d L_{2}^{S}}{d \bar{L}_{2}}+\left[\frac{\alpha}{\beta}+S_{1}^{\prime}(.)\right] \frac{d L_{1}^{S}}{d \bar{L}_{2}}+\sigma \frac{d E}{d \bar{L}_{2}}=\frac{\alpha}{\beta}} \\
\Omega_{2} \frac{d L_{2}^{S}}{d \bar{L}_{2}}+\frac{f^{\prime \prime}(.)}{\sigma+r}\left[1+\frac{\beta}{\alpha} S_{2}^{\prime}(.)\right] \frac{d E}{d \bar{L}_{2}}=\alpha \beta u_{2}^{\prime \prime}(.) \\
\Omega_{1} \frac{d L_{1}^{S}}{d \bar{L}_{2}}+\frac{f^{\prime \prime}(.)}{\sigma+r}\left[1+\frac{\beta}{\alpha} S_{1}^{\prime}(.)\right] \frac{d E}{d \bar{L}_{2}}=0
\end{array}
$$




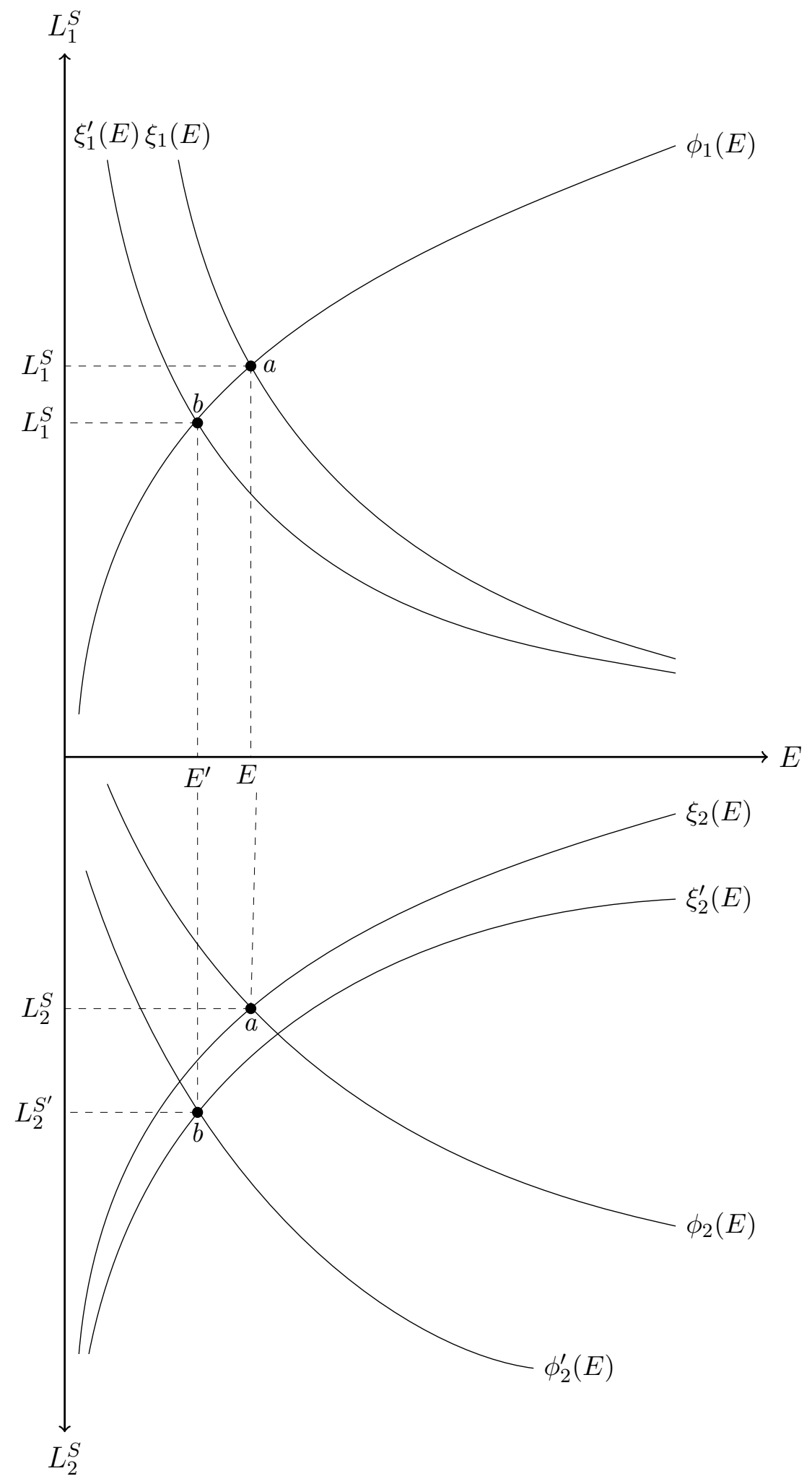

Figure 1: Autarky steady-state equilibrium and the effects of a labor endowment increase in the south. 
where $\Omega_{j}=(\beta / \alpha) f^{\prime}(.) S_{j}^{\prime \prime}() /.(\sigma+r)+\alpha \beta u_{j}^{\prime \prime}()<0,. j=1,2$. By solving the above system of equations, we obtain:

$$
\begin{array}{r}
\frac{d L_{2}^{S}}{d \bar{L}_{2}}=\frac{1}{|H|}\left[\alpha \beta \sigma \Omega_{1} u_{2}^{\prime \prime}(.)-\beta^{2}\left(\Omega_{1}\left(\frac{\alpha}{\beta}+S_{2}^{\prime}(.)\right)+u_{2}^{\prime \prime}(.)\left(\frac{\alpha}{\beta}+S_{1}^{\prime}(.)\right)^{2}\right) \frac{f^{\prime \prime}}{\sigma+r}\right]>0 \\
\frac{d L_{1}^{S}}{d \bar{L}_{2}}=\frac{1}{|H|}\left[\beta S_{2}^{\prime}(.) u_{2}^{\prime \prime}(.)-\frac{f^{\prime} S_{2}^{\prime \prime}(.)}{\alpha(\sigma+r)}\right]\left(\frac{\alpha}{\beta}+S_{1}(.)\right) \frac{f^{\prime \prime}}{\sigma+r} \gtreqless 0 \\
\frac{d E}{d \bar{L}_{2}}=\frac{\alpha \Omega_{1}}{|H|}\left[\frac{f^{\prime} S_{2}^{\prime \prime}(.)}{\alpha}-\beta S_{2}^{\prime}(.) u_{2}^{\prime \prime}(.)\right] \\
\end{array}
$$

where $|H|=\sigma \Omega_{1} \Omega_{2}-\frac{\beta}{\alpha}\left[\Omega_{1}\left(\frac{\alpha}{\beta}+S_{2}^{\prime}(.)\right)^{2}+\Omega_{2}\left(\frac{\alpha}{\beta}+S_{1}^{\prime}(.)\right)^{2}\right] \frac{f^{\prime \prime}}{\sigma+r}>0$. Thus, $d L_{2}^{S} / d \bar{L}_{2}>0$, while the signs of $d L_{1}^{S} / d \bar{L}_{2}$ and $d E / d \bar{L}_{2}$ are (apparently) ambiguous. Lastly, note that $d L_{2}^{S} / d \bar{L}_{2}<1$, which implies that $d L_{2}^{Y} / d \bar{L}_{2}>0$, indicating that $d Y_{2} / d \bar{L}_{2}>0$. Thus, we conclude that $d C_{2} / d \bar{L}_{2}>0$.

Considering our problem from a different perspective sheds additional light on the ambiguous effects represented by equations (26) and (27). By totally differentiating $\phi_{1}$ (i.e., equation (15) after substituting for the steady-state level of $\lambda_{1}$ from (16)), it is straightforward to show that $d L_{1}^{S} / d \bar{L}_{2}=0$ at equilibrium. That is, $\phi_{1}$ in Figure 1 does not shift in a local neighborhood of the initial equilibrium. However, totally differentiating $\xi_{1}$ (i.e., equation (7) when $\dot{E}=0$ ) results in:

$$
\frac{d L_{1}^{S}}{d \bar{L}_{2}}=-\frac{S_{2}^{\prime}(.)}{\frac{\alpha}{\beta}+S_{1}^{\prime}(.)} \frac{d L_{2}^{S}}{d \bar{L}_{2}}
$$

This implies that at the initial equilibrium $d L_{1}^{S} / d \bar{L}_{2}<0$ since we have already established from equation (25) that $d L_{2}^{S} / d \bar{L}_{2}>0$. Collectively these results imply that both $L_{1}^{S}$ and $E$ decrease at the new steady-state equilibrium (see Figure 1). Reduction in $L_{1}^{S}$ also implies that consumption of the finished good in region 1 increases.

The effects of an expansion in region 2's labor endowment are depicted in Figure 1, where the upper (lower) panel depicts the resulting effects in region 1(2). An increase in region 2's 
labor endowment shifts $\phi_{2}$ upward to, say, $\phi_{2}^{\prime}$, while $\xi_{2}$ also shifts upward to $\xi_{2}^{\prime}$. The new steady-state equilibrium is identified as point $b$. Region 2's steady-state carbon sequestration level therefore increases. While $\phi_{1}$ does not shift for region 1 in the figure's upper panel, $\xi_{1}$ shifts downward as established by the proof of Proposition 3. Consequently, $L_{1}^{S}$ and the global carbon stock $E$ both fall.

Intuitively, with wages adjusting in equilibrium to ensure full employment of labor in each region, region 2's expanded labor force is drawn into production of both the finished good and carbon sequestration. As for region 1, our result depicts a classic case of free-riding behavior since this region reduces its labor allocation to carbon sequestration. However, region 1's free-riding behavior is not strong enough to offset region 2's direct effect on $E$ due to region 2's increased allocation of labor to sequestration. As a result, $E$ decreases.

Finally, it is of interest to explore the effects of a change in a given region's sequestration productivity on the autarky steady-state equilibrium. As in the previous analysis, we assume all other aspects for these two regions are the same. The following proposition formally states the implications of such a change.

Proposition 4. An increase in region j's carbon sequestration productivity has ambiguous effects on region j's steady-state sequestration and finished-good production levels, but leads to a reduction in the equilibrium global carbon stock. Moreover, the increase in region $j$ 's sequestration productivity leads to a decrease (increase) region $k$ 's, $k \neq j$, level of carbon sequestration (finished-good consumption).

Proof. As in the proof of Proposition 3, and without loss of generality, assume region 2 experiences an exogenous increase in carbon sequestration productivity. We start by parameterizing $S_{2}($.$) as S_{2}\left(L_{2}^{S} ; \delta_{2}\right)$ where $\partial S_{2} / \partial \delta_{2}>0$ and $\frac{\partial^{2} S_{2}}{\partial L_{2}^{S} \partial \delta_{2}}>0$, thus isolating the marginal effect on sequestration productivity. We then have:

$$
\begin{array}{r}
\frac{d L_{2}^{S}}{d \delta_{2}}=\frac{\beta}{\alpha(\sigma+r)|H|}\left[\Omega_{1} f^{\prime \prime}\left(\frac{\alpha}{\beta}+\frac{\partial S_{2}}{\partial L_{2}^{S}}\right) \frac{\partial S_{2}}{\partial \delta_{2}}-f^{\prime}\left(\frac{\beta f^{\prime \prime}}{\alpha(\sigma+r)}\left(\frac{\alpha}{\beta}+\frac{\partial S_{1}}{\partial L_{1}^{S}}\right)-\sigma \Omega_{1}\right) \frac{\partial^{2} S_{2}}{\partial L_{2}^{S} \partial \delta_{2}}\right] \gtreqless 0(28) \\
\frac{d L_{1}^{S}}{d \delta_{2}}=\frac{\beta\left(\frac{\alpha}{\beta}+\frac{\partial S_{1}}{\partial L_{1}^{S}}\right) f^{\prime \prime}}{\alpha(\sigma+r)|H|}\left[\Omega_{2} \frac{\partial S_{2}}{\partial \delta_{2}}-\frac{\beta}{\alpha} \frac{f^{\prime}}{\sigma+r}\left(\frac{\alpha}{\beta}+\frac{\partial S_{2}}{\partial L_{2}^{S}}\right) \frac{\partial^{2} S_{2}}{\partial L_{2}^{S} \partial \delta_{2}}\right]<0(29)
\end{array}
$$




$$
\frac{d E}{d \delta_{2}}=\frac{-\Omega_{1}}{|H|}\left[\frac{\beta f^{\prime}(.)}{\alpha(\sigma+r)}\left(\frac{\alpha}{\beta}+\frac{\partial S_{2}}{\partial L_{2}^{S}}\right) \frac{\partial^{2} S_{2}}{\partial L_{2}^{S} \partial \delta_{2}}-\Omega_{2} \frac{\partial S_{2}}{\partial \delta_{2}}\right]<0(30)
$$

where $|H|$ and $\Omega_{j}, j=1,2$ are defined as in the preceding proposition proofs. Evidently, $d L_{1}^{S} / d \delta_{2}<0$ and $d E / d \delta_{2}<0$, while the sign of $d L_{2}^{S} / d \delta_{2}$ is indeterminate.

Ambiguity in the direction of change in the level of region 2's carbon sequestration (and thus finished-good consumption) stems from the fact that given a small (large) enough $\beta(\sigma)$ value an increase in its sequestration productivity may enable region 2 to reduce $L_{2}^{S}$ and still achieve a corresponding reduction in $E$ (see (12) with $\dot{E}=0) .{ }^{9}$ Thus, region 2 is capable of capitalizing on its innovation in sequestration productivity by balancing its response shifting some of its labor resource to production of the finished good - while still inducing a decrease in the global carbon stock in the face of region 1's free-riding response.

Developing nations differ in terms of their relative carbon sequestration productivities, hence in addition to illustrating the effect of a technological change in sequestration the above proposition also relates to patterns of comparative advantage. At any given ratio of carbon sequestration to finished-good consumption, a region with a higher marginal sequestration productivity must have a lower opportunity cost of sequestration in an autarky equilibrium. The proposition has further policy implications. It suggests, for example, that in an autarkic setting transfers of, or investment in, sequestration technologies in the South could be effective in reducing the global carbon stock while at the same time enhancing the South's production of the finished good. In other words, enhancing the South's carbon sequestration productivity could be a "win-win" in terms of improving the global environment and increasing the South's standard-of-living.

Before explicitly incorporating international trade in carbon permits and the finished goods into our model we draw an important relationship between the price side of our

\footnotetext{
${ }^{9}$ It can similarly be shown that an increase in finished-good productivity has an ambiguous effect on both carbon sequestration and finished-good consumption levels, as well as on the global carbon stock.
} 
autarkic model and its quantity side. ${ }^{10}$ Denote the relative permit price by $\tau_{j}=i_{j} / p_{j}, j=$ 1,2. The following proposition formally addresses this relationship.

Proposition 5. There exists a one-to-one relationship between the relative carbon permit price and employment in carbon sequestration in region $j=1,2$, at any time $t$, given by $\tau_{j}=1 /\left(1 / \beta+S_{j}^{\prime}\left(L_{j}^{S}\right) / \alpha\right)$.

Proof. A competitive market for the final good requires that the final good price at any time $t$ be given by:

$$
p_{j}=\frac{w_{j}}{\alpha}+\frac{i_{j}}{\beta} \quad j=1,2
$$

implying that $w_{j}=\alpha\left(p_{j}-i_{j} / \beta\right)$. This implies from the labor market equilibrium and labor mobility that:

$$
i_{j} S_{j}^{\prime}\left(L_{j}^{S}\right)=w_{j}=\alpha\left(p_{j}-i_{j} / \beta\right) \quad j=1,2
$$

which in turn implies the result.

\section{International Trade in Carbon Permits}

The final step in our analysis is to modify our autarky model to incorporate the possibility of international trade in both the finished good and in carbon permits. We restrict our analysis to the case of free international trade. Throughout the remainder of the paper we maintain that the sole difference between the North and South is higher marginal sequestration productivity in the South for any given input level. As highlighted in the following proposition, this difference is sufficient to guarantee that the South (North) has a comparative advantage in carbon sequestration (the finished good) at any given point in time.

Proposition 6. Let $S_{1}^{\prime}\left(L^{S}\right)<S_{2}^{\prime}\left(L^{S}\right), \forall L^{S}>0$. Then, the South (North) has comparative advantage in carbon sequestration(the finished good) at any time $t$.

\footnotetext{
${ }^{10} \mathrm{We}$ are grateful to an anonymous referee for pointing out this relationship.
} 
Proof. It directly follows from Proposition 5 that $\hat{\tau}_{1}(t)>\hat{\tau}_{2}(t), \forall t$, implying that the South South (North) has comparative advantage in carbon sequestration (the finished good) at any time $t$.

Following the standard theory of trade the South is therefore a net exporter (importer) of carbon permits (the finished good) to (from) the North. In turn, region $j$ 's consumption level is given by $C_{j}(t)=Y_{j}(t)+m_{j}(t), \forall t, j=1,2$, where $m_{j}(t)$ is the quantity of trade in the finished good by region $j=1,2$. Note that $m_{1}(t)<0$ and $m_{2}(t)>0$, indicating that the North (South) is a net exporter (importer) of the finished good. Furthermore, net emissions in each region (i.e, carbon emissions net of trade in permits) is given by $e_{j}(t)-x_{j}(t)=\alpha\left(\bar{L}-L_{j}^{S}(t)\right) / \beta$, where $x_{j}(t)$ is region $j$ 's quantity of trade in permits. Since the South (North) is a net exporter (importer) of carbon permits, we have $x_{1}<0$ and $x_{2}>0 .{ }^{11}$ Finally, the global market-clearing conditions for the finished good and permit markets as well as the trade-balance condition for each country require that, respectively:

$$
\begin{array}{r}
m_{1}(t)+m_{2}(t)=0 \\
x_{1}(t)+x_{2}(t)=0 \\
m_{j}(t)=\tau(t) x_{j}(t) \quad j=1,2
\end{array}
$$

where $\tau$ is the relative world price of carbon. It follows from equation (31) and (32) that $m_{1}=-m_{2} \equiv m$ and $x_{1}=-x_{2} \equiv x$. Substituting these expressions into (33) and noting the implicit dependence of $\tau$ on $L_{j}^{S}, j=1,2$, we can rewrite (33) most succinctly as $m=$ $\Lambda\left(L_{j}^{S}\right)=\tau\left(L_{j}^{S}\right) x\left(L_{j}^{S}\right), j=1,2$. This specification captures the essence of the effect of a region's choice of carbon sequestration on the permit market. Subject to (13), region $j$ 's

\footnotetext{
${ }^{11}$ Note that, in contrast to the finished good, exports of carbon permits are defined to be positive, while imports are defined to be negative. For example, if the South exports one carbon permit to the North, then the South's carbon emissions must fall by one unit, implying that $L_{2}^{S}(t)\left(L_{1}^{S}(t)\right)$ must increase (decrease) by $\alpha / \beta$. It is also worth noting that the total quantity of permits allocated is both implicit and endogenously determined in the context of this model's permit market (see Caplan and Silva, 2005, and Caplan, 2006, for early examples of this approach).
} 
current-value Hamiltonian as it engages in free trade can be written as:

$$
H_{j}=\left[u\left(Y_{j}+m_{j}\right)-f(E)\right]+\lambda\left(\sum_{j=1}^{2} e_{j}-\sum_{j=1}^{2} S_{j}\left(L_{j}^{S}\right)-\sigma E\right),
$$

resulting in region $j$ 's first order conditions,

$$
\begin{array}{r}
{\left[\frac{d m_{j}}{d(\Lambda)} \frac{d(\Lambda)}{d L_{j}^{S}}-\alpha\right] u^{\prime}(.)-\lambda_{j}\left[\frac{\alpha}{\beta}+S_{j}^{\prime}\left(L_{j}^{S}\right)\right]=0} \\
\dot{\lambda}_{j}=f^{\prime}(E)+\lambda_{j}(\sigma+r)
\end{array}
$$

as well as equations (13) and the global carbon stock law of motion. The transversality condition is again given by $\lim _{t \rightarrow \infty} \lambda_{j}(t) E(t)=0, j=1,2$. Further, from (36) we note that in the steady state $\lambda_{j}<0, j=1,2$.

As in the preceding section, we start with some characterizations of the free-trade equilibrium path before turning to a characterization of the steady-state. The following proposition draws a comparison between the autarky and free-trade equilibrium paths for both the North and South. Recall that a circumflex denotes autarky values. Let a tilde denote the corresponding free-trade values.

Proposition 7. Assume that $S_{1}^{\prime}\left(L^{S}\right)<S_{2}^{\prime}\left(L^{S}\right), \forall L^{S}>0$. Then for all $t>t(0)$ : (i) $\tilde{S}_{1}(t)<\hat{S}_{1}(t)<\hat{S}_{2}(t)<\tilde{S}_{2}(t)$, and $(i i) \tilde{Y}_{1}(t)>\hat{Y}_{1}(t)>\hat{Y}_{2}(t)>\tilde{Y}_{2}(t)$.

Proof. Begin by noting that the second inequalities in both (i) and (ii) follow directly from Proposition 1. Thus, we need only verify the first and last inequalities in (i) and (ii).

(i) Since $\hat{\tau}_{2}(t)<\tau(t)<\hat{\tau}_{1}(t)$ for any $t$ along the equilibrium path. It follows from Proposition 5 that $\alpha / S_{2}^{\prime}\left(\hat{L}_{2}^{S}(t)\right)<\alpha / S_{2}^{\prime}\left(\tilde{L}_{2}^{S}(t)\right)$, implying $S_{2}^{\prime}\left(\tilde{L}_{2}^{S}(t)\right)<S_{2}^{\prime}\left(\hat{L}_{2}^{S}(t)\right)$. This, along with the diminishing marginal sequestration productivity, implies $\tilde{L}_{2}^{S}(t)>\hat{L}_{2}^{S}(t)$, $\forall t>t(0)$. Similarly, it can be shown that $\hat{L}_{1}^{S}(t)>\tilde{L}_{1}^{S}(t), \forall t>t(0)$. Thus, we have $\tilde{L}_{1}^{S}(t)<\hat{L}_{1}^{S}(t)<\hat{L}_{2}^{S}(t)<\tilde{L}_{2}^{S}(t), \forall t>t(0)$. Therefore, it follows from positive marginal sequestration productivity that $\tilde{S}_{1}(t)<\hat{S}_{1}(t)<\hat{S}_{2}(t)<\tilde{S}_{2}(t)$. 
(ii) Since we have established that $\tilde{L}_{1}^{S}(t)<\hat{L}_{1}^{S}(t)<\hat{L}_{2}^{S}(t)<\tilde{L}_{2}^{S}(t), \forall t>t(0)$, it follows from equation (9) that $\tilde{L}_{1}^{Y}(t)>\hat{L}_{1}^{Y}(t)>\hat{L}_{2}^{Y}(t)>\tilde{L}_{2}^{Y}(t), \forall t>t(0)$, implying that $\tilde{Y}_{1}(t)>\hat{Y}_{1}(t)>\hat{Y}_{2}(t)>\tilde{Y}_{2}(t), \forall t>t(0)$.

This proposition indicates that the regions will indeed exploit their respective comparative advantages in moving from an autarkic to a free-trade equilibrium. In particular, the North reallocates its resources to produce relatively more of the finished good, while the South reallocates toward the production of carbon sequestration.

Next we consider the effect of trade in goods and carbon permits on the global carbon stock. While at any point in time both regional governments choose their optimal sequestration and thus emission levels, it is not entirely obvious what happens when both regions engage in trade. In the following proposition we address the effects of trade liberalization in the finished good and carbon permit markets on the global carbon stock by considering a small departure from an autarkic equilibrium at any point in time.

Proposition 8. Let $S_{1}^{\prime}\left(L^{S}\right)<S_{2}^{\prime}\left(L^{S}\right), \forall L^{S}>0$. A sufficiently small departure from an autarky equilibrium by the regions at any time $t$ in response to the opening of trade reduces the global carbon stock at that time as well as at the steady-state trading equilibrium.

Proof. Let the North and South liberalize slightly from the autarky equilibrium at time $t$. To show the effect on $E$, differentiate the carbon stock law of motion and simplify to obtain:

$$
d \dot{E}+\sigma d E(t)=-\frac{\alpha}{\beta}\left(d L_{1}^{S}+d L_{2}^{S}\right)-\alpha\left(\frac{d L_{1}^{S}}{\hat{\tau}_{1}(1)}+\frac{d L_{2}^{S}}{\hat{\tau}_{2}(1)}\right)
$$

Note from Proposition 7 that $d L_{1}^{S}<0$ and $d L_{2}^{S}>0$. Now, as we consider sufficiently small changes, let $d L_{2}^{S}=-d L_{1}^{S}=\varepsilon>0$. It then follows from equation (37) that $d E \approx$ $\alpha\left(\varepsilon / \hat{\tau}_{1}-\varepsilon / \hat{\tau}_{2}\right) / \sigma<0$, where the inequality follows directly from the proof of Proposition 6 . In the steady-state equilibrium the equality is strict, i.e., $d E=\alpha\left(\varepsilon / \hat{\tau}_{1}-\varepsilon / \hat{\tau}_{2}\right) / \sigma<0$. 
In other words, as the regions incrementally adjust their labor allocations to exploit their respective comparative advantages in response to the opening of free trade, the resulting allocations reflect the greater degree of specialization that occurs as a result. Given the simplifying assumptions adopted in Section 3, these adjustments in turn lead to a reduction in the global carbon stock as the world economy opens up for trade. The result is intuitive. Since production technologies are assumed identical across regions, the production (including its relocation) effect on the carbon stock is outweighed by increased sequestration under the free trade regime. Of course if production technology is sufficiently dirtier in the North than in the South, the former effect could outweigh the latter. In this case the carbon stock would increase.

As in the preceding section, we next address the existence and uniqueness of the global economy's steady-state free-trade equilibrium. Global stability conditions for this equilibrium are derived in the technical appendix.

Let $L_{j}^{S}=\tilde{\phi}_{j}(E)$ be the $L_{j}^{S}-E$ locus along which $\dot{\lambda}=0$ and $L_{j}^{S}=\tilde{\xi}_{j}(E)$ be the locus along which $\dot{E}=0$ for region $j=1,2$. The following lemmas characterize $\tilde{\xi}_{j}$ and $\tilde{\phi}_{j}, j=1,2$.

Lemma 3. (i) $\tilde{\xi}_{j}(0)>0$ and $\tilde{\xi}_{j}^{-1}(0)>0$ for $j=1,2$, and $(i i) \tilde{\xi}_{j}(E), j=1,2$, is monotonically decreasing and convex in E.

Proof. (i) Using equation (6) it is straightforward to verify that $\tilde{\xi}_{j}^{-1}(0)=\sum_{j=1}^{2} e_{j} / \sigma-$ $\frac{S_{k}\left(L_{k}^{S}\right)}{\sigma}=\alpha\left(L_{k}^{Y}+\bar{L}\right) /(\beta \sigma)+S_{k}\left(L_{k}^{S}\right)>0, j, k=1,2, j \neq k$. It also follows from the carbon stock law of motion that $\sum_{j=1}^{2} e_{j}-\sum_{j=1}^{2} S_{j}\left(L_{j}^{S}\right)=0$ if $\dot{E}=E=0$. This in turn implies that $S_{j}\left(L_{j}^{S}\right)=\sum_{j=1}^{2} e_{j}-S_{k}\left(L_{k}^{S}\right)>0, j, k=1,2, j \neq k$. However, the inequality is true iff $L_{j}^{S}>0$, therefore $\tilde{\xi}_{j}(0)>0, j=1,2$.

(ii) Set $\dot{E}=0$ in global carbon stock law of motion, totally differentiate the resulting equation, and rearrange to obtain:

$$
\tilde{\xi}_{j}^{\prime}(E)=\frac{-\sigma}{\frac{\alpha}{\beta}+S_{j}^{\prime}(.)}<0 .
$$


To verify the convexity of $\tilde{\xi}_{j}(E)$, differentiate $(38)$ with respect to $E$ to obtain $\tilde{\xi}_{j}^{\prime \prime}(E)=$ $\frac{-\sigma^{2} S_{j}^{\prime \prime}(.)}{\left(\alpha / \beta+S_{j}^{\prime}(.)\right)^{3}}>0, j=1,2$.

The following lemma likewise addresses some important properties of $\tilde{\phi}_{j}, j=1,2$.

Lemma 4. Let $u($.$) and S_{j}($.$) satisfy their respective Inada conditions. Then, (i) \tilde{\phi}_{j}^{-1}(0)=0$ as $L_{j}^{S} \longrightarrow 0$, (ii) $\lim _{E \rightarrow \infty} \tilde{\phi}_{j}(E)=\bar{L}_{j}$, and (iii) $\tilde{\phi}_{j}^{\prime}(E)>0$ if $\sigma$ and $r$ are sufficiently small. Proof. By setting $\dot{\lambda}_{j}=0$ in (36) and using equation (35) we obtain:

$$
\left[\frac{d m}{d(\Lambda)} \frac{d(\Lambda)}{d L_{j}^{S}}-\alpha\right] u^{\prime}(.)+\frac{f^{\prime}(E)}{\sigma+r}\left[\frac{\alpha}{\beta}+S_{j}^{\prime}\left(L_{j}^{S}\right)\right]=0 .
$$

(i) Recall that $\lim _{L_{j}^{S} \rightarrow 0} S_{j}^{\prime}\left(L_{j}^{S}\right)=\infty$. Thus, the second bracketed term in (39) approaches infinity as $L_{j}^{S} \rightarrow 0$. Since $\lim _{L_{j}^{S} \rightarrow 0} \frac{d \Lambda}{d L_{j}^{S}}$ is finite, for equation (39) to hold, we must have $f^{\prime}(E)=0$ as $L_{S} \rightarrow 0$, which is true if and only if $E=0$, implying $\tilde{\phi}_{j}^{-1}(0)=0$.

(ii) Note that as $E \rightarrow \infty$ the second term in (39) approaches $+\infty$ via our maintained assumptions on $f($.$) . Therefore, for (39) to hold as E \rightarrow \infty$ we must have the equation's first expression simultaneously approach $-\infty$ as $E \rightarrow \infty$. In order for (39) to hold, the first bracketed expression must be negative at a steady-state equilibrium, implying that we must have $u^{\prime}(.) \rightarrow \infty$, which in turn implies $C \rightarrow 0$. However, this would be the case if and only if $L_{j}^{Y}=m=0$, that is, $L_{j}^{S}=\bar{L}_{j}$. Thus, we conclude that $\lim _{E \rightarrow \infty} \tilde{\phi}_{j}(E)=\bar{L}_{j}$.

(iii) Totally differentiating (39) and rearranging we obtain:

$$
\tilde{\phi}_{j}^{\prime}(E)=-\frac{\left[\frac{\alpha}{\beta}+S_{j}^{\prime}\left(L_{j}^{S}\right)\right] f^{\prime \prime}(.)}{\Psi_{j}}
$$

where:

$$
\Psi_{j}=(\sigma+r) \Delta_{j} u^{\prime \prime}(.)+(\sigma+r) \Omega_{j} u^{\prime}(.)+f^{\prime}(.) S_{j}^{\prime \prime}(.)
$$




$$
\begin{array}{r}
\Delta_{j}=\left([d m / d \Lambda]\left[d \Lambda / d L_{j}^{S}\right]-\alpha\right)^{2}>0 \\
\Omega_{j}=\left[d^{2} m / d \Lambda^{2}\right]\left[d \Lambda / d L_{j}^{S}\right]^{2}+[d m / d \Lambda]\left[d^{2} \Lambda / d L_{j}^{S 2}\right]
\end{array}
$$

The numerator of (40) is positive. The first and third terms of $\Psi_{j}$ are negative while the second term is ambiguous. However, the first and last terms will dominate the second term for sufficiently small $\sigma$ and $r$. Thus, $\tilde{\phi}_{j}^{\prime}(E)>0$ if the carbon stock naturally decays at a sufficiently slow rate.

We now turn to the existence and uniqueness of a steady-state free-trade equilibrium. The following proposition addresses the question of existence under the condition that the South is a net importer (exporter) of the finished good (carbon permits) as stated formally in Proposition 9.12

Proposition 9. Assume that $u($.$) and S_{j}(),. j=1,2$, meet their respective Inada conditions. Then there exists a steady-state free-trade equilibrium in which the South's carbon sequestration level is positive given that it is a net importer (exporter) of the finished good (carbon permits). Moreover, the equilibrium is unique for sufficiently small $\sigma$ and $r$.

Proof. At a steady-state equilibrium we have $L_{j}^{S}=\tilde{\phi}_{j}\left(\tilde{\xi}_{j}^{-1}\left(L_{j}^{S}\right)\right), j=1,2$. Part (i) of Lemma 3 as well as parts (i) and (ii) of Lemma 4 guarantee the existence of an equilibrium (i.e., a fixed point of the composite function $\left.\tilde{\phi}_{j}\left(\tilde{\xi}_{j}^{-1}().\right)\right)$ at which region $j$ 's sequestration level is positive. Moreover, part (ii) of Lemma 3 and part (iii) of Lemma 4 ensure that such a fixed point is unique for sufficiently small $\sigma$ and $r$.

In addition to illustrating the properties of the autarky equilibrium, we can think of point $a$ in Figure 1 as depicting our unique, free-trade, steady-state equilibrium (replacing $\phi$ with

\footnotetext{
${ }^{12}$ Note that the lack of a more general uniqueness property for the free-trade equilibrium is consistent with static, neoclassical trade models. If instead we assume a small, open Southern economy, the international relative price of a carbon permit is determined exogenously. It would then follow that $\Delta_{j}=\alpha^{2}, \Omega_{j}=0$, and $\Psi_{j}<0$ in equation (40), implying $\tilde{\phi}_{j}^{\prime}(E)>0, \forall \sigma \in(0,1)$. This ensures a unique steady-state equilibrium for any $\sigma$.
} 
$\tilde{\phi}$ and $\xi$ with $\tilde{\xi}$ ) when $\sigma$ and $r$ are sufficiently small. Recall that a higher $\sigma$ implies that carbon sequestration is less valuable. At the extreme, if $\sigma=1$, then carbon emissions are completely absorbed by nature, thus rendering sequestration irrelevant. The requirement of a smaller discount rate implies that future outcomes are more important. Thus, if neither of these requirements is met, then carbon permit market may be irrelevant.

As a final observation, evidently both regions benefit from this trading arrangement when compared with the status quo of no carbon sequestration and international permit trading, assuming that our earlier assumption guaranteeing a Southern comparative advantage in sequestration is met (see Proposition 6). This conclusion follows directly from the solution to our dynamic optimization problem. Assume that the condition of Proposition 6 is met, resulting in Southern comparative advantage in carbon sequestration. It follows that at the outset of trade the relative carbon price is lower in the South than in the North. Therefore, under free trade the South imports (exports) the finished good (carbon permits) and through classic gains from trade experiences an increase in welfare. Higher welfare for both regions in this equilibrium follows from the fact that a zero time path for carbon sequestration (i.e., $\left.L_{j}^{S}(t)=0, j=1,2 \forall t\right)$ is technically feasible for both the autarky and the free-trade scenarios in both regions.

However, in both scenarios the optimal paths are instead characterized by positive levels of carbon sequestration. This implies, by the definition of optimality, that regional welfare is improved (for both regions) with carbon sequestration under both free trade and autarky. Free trade further enhances the South's welfare through the gains-from-trade pathway. In essence, there are two sources of gain. On the one hand, optimizing emission levels (i.e., internalizing environmental externalities) leads to welfare improvement. On the other hand, both regions enjoy the classical gains from trade. We thus have the following formal corollary.

Corollary 1. Assume that $S_{1}^{\prime}\left(L^{S}\right)<S_{2}^{\prime}\left(L^{S}\right), \forall L^{S}>0$. Then there exists a global system of carbon sequestration and carbon permit trading under which welfare for both North and South improves. 
Hence, compared to a global economy with neither global cap-and-trade nor a market for carbon sequestration (the current status quo), there are two sources of gains for the South. One is due to an improvement in the domestic trade-off between consumption of the finished good and its contribution to environmental damage (i.e., the South benefits directly from increased carbon sequestration). Another results from engaging in trade with the North by exporting carbon permits and importing the finished good. Of course the important point is that the existence of a global permit market makes it in the developing region's interest to increase its sequestration and trade carbon permits.

One might ask, given this result, why are Southern regions typically opposed to international environmental treaties such as the UN Framework Convention on Climate Change (UNFCCC)? One reason could be that these agreements often involve a multitude of articles

addressing various aspects of global carbon emission management, aspects of which may be objectionable to developing nations. Our model is designed to address a more specific question. If an international carbon permit market is put in place, would developing nations have an incentive to participate all else equal? Our theory suggests that the answer is yes, and illustrates the mechanism for why.

\section{Conclusions}

We construct a dynamic game between Northern (developed) and Southern (developing) regions within a general-equilibrium framework. We show how the South may develop a dynamic comparative advantage in the production of carbon sequestration and thereby engender an inherent incentive to join with the North in a global carbon trading market. In particular, we characterize the equilibrium path as well as the steady-state equilibrium under both autarky and free trade, and derive the underlying conditions for the South's dynamic comparative advantage in sequestration.

Importantly, we show that under free trade - where the South exports carbon permits - 
the global carbon stock falls relative to autarky, without requiring an explicit, exogeneous global carbon cap. Moreover, given a standard set of assumptions, a unique steady-state free-trade equilibrium exists where the South exports carbon permits and imports finished goods, provided that the natural rate of decay (i.e., atmospheric assimilation) of carbon is sufficiently slow. Both the North and the South experience increases in regional welfare relative to autarky and the absence of carbon sequestration. In the context of our model, the policy implication is that no other enticements (e.g., foreign aid, etc.) would be required to induce Southern cooperation in the fight against climate change. Needless to say, the formation of such a global carbon permit market may also lead to further socially desirable outcomes, such as protection of other endangered natural resources (e.g., tropical rainforests, marginal agricultural lands, etc.). ${ }^{13}$

We have tried to maintain a balance between tractability and realism in deriving our analytical results. The model we present captures the essential elements of the joint carbon sequestration and carbon permit market problem. However, it is generally the case in economic dynamics that relatively strong assumptions must be imposed when pursuing an analytical solution, and the model presented in this paper is no exception. The analysis could be extended, for example, by incorporating tariffs or adding capital accumulation to the model. Several of the model's more restrictive assumptions, such as identical finished good technologies, emissions productivities, and welfare functions, could also be relaxed in extended versions of our basic model. Relaxing these these assumptions would evince the sensitivity of our results in more realistic settings. Of course the trade-offs associated with these adjustments is that as extra dimensions are added to our dynamical system we would need to appeal to computational and numerical analyses as necessary supplements to our underlying conceptual model.

\footnotetext{
${ }^{13}$ Furthermore, by having created a market for the global externality with endogenously determined initial permit allocations, the model's free-trade equilibrium results in full internalization of the damages associated with the global carbon stock, and is therefore Pareto efficient.
} 


\section{Technical Appendix}

To determine the local stability properties of the system of differential equations (7) and (16) in Section 3 at the steady-state equilibrium, we evaluate the determinant of the system's Jacobian matrix $(J)$ taking into account $\frac{\partial L_{j}^{S}}{\partial \lambda_{j}}<0$ from $(15)$,

$$
J=\left|\begin{array}{cc}
-\sigma & -\left[\frac{\alpha}{\beta}+S^{\prime}(.)\right] \frac{\partial L_{j}^{S}}{\partial \lambda_{j}} \\
f^{\prime \prime}(.) & \sigma+r
\end{array}\right|<0 .
$$

$|J|<0$ denotes saddle-point stability. The same Jacobian matrix results for the system of equations (36) and the carbon stock law of motion in Section 4. However, in this case the expression for $\frac{\partial L_{j}^{S}}{\partial \lambda_{j}}$ (derived through total differentiation of $\left.(35)\right)$ is:

$$
\frac{\partial L_{j}^{S}}{\partial \lambda_{j}}=\frac{\frac{\alpha}{\beta}+S^{\prime}(.)}{\Delta u^{\prime \prime}(.)+\Omega u^{\prime}(.)+\frac{f^{\prime}(.)}{\sigma+r} S^{\prime \prime}(.)}
$$

where $\Omega$ and $\Delta$ are defined as in the proof of Lemma 4. A sufficient condition for $\frac{\partial L_{S_{s}}}{\partial \lambda_{s}}<0$ entails sufficiently small $\sigma$ and $r$. This in turn would similarly imply $|J|<0$.

To test for global stability of the systems in both Sections 3 and 4, respectively, we use Brock and Scheinkman's (1976) positive definiteness test, where:

$$
|Q|=\left|\begin{array}{cc}
-\frac{\partial^{2} H}{\partial E^{2}} & \frac{r}{2} \\
\frac{r}{2} & \frac{\partial^{2} H}{\partial \lambda_{j}^{2}}
\end{array}\right|>0
$$

implies global stability. Considering first the autarky case of Section 3, we differentiate (14) twice with respect to $E$ in order to obtain $\partial^{2} H / \partial E^{2}=-f^{\prime \prime}(E)<0$. Similarly, differentiating (14) twice with respect to $\lambda$ and using the envelope theorem we obtain:

$$
\frac{\partial^{2} H}{\partial \lambda^{2}}=-\left[\frac{\alpha}{\beta}+S^{\prime}\left(L_{S}\right)\right] \frac{\partial L_{j}^{S}}{\partial \lambda_{j}} .
$$

Recalling that $\partial L_{j}^{S} / \partial \lambda_{j}<0$ under autarky, we conclude that $\partial^{2} H / \partial \lambda_{j}^{2}>0$. These results 
imply that the global stability condition holds for the autarky problem for sufficiently small $r$.

Finally, considering the free-trade case of Section 4, the condition on the system's determinant defined by (42) holds, but only for sufficiently small $\sigma$ and $r$, since in this case we also have $\partial^{2} H / \partial E^{2}=-f^{\prime \prime}(E)<0$ and equations (41) and (43) hold. 


\section{References}

Acemoglu, D., Aghion, P., Bursztyn, L., and D. Hemous (2012), "The Environment and Directed Technical Change," American Economic Review 102(1): 131-166.

Barrett, S. (1994), "Self-Enforcing International Environmental Agreements," Oxford Economic Papers 46, 878-894,

Batabyal, A.A., (2000), The Economics of International Environmental Agreements, London, Ashgate Publishing Limited.

Batabyal, A.A., (1997), "Developing Countries and Environmental Protection: The Effects of Budget Balance and Pollution Ceiling Constraints," Journal of Development Economics 54: $285-305$.

Batabyal, A.A., Beladi, H., (2002), “A Dynamic Analysis of Protection and Environmental Policy in a Small Trading Developing Country," European Journal of Operational Research 143: $197-209$.

Beladi, H. Liu, L. and R. Oladi (2013), "On Pollution Permits and Abatement," Economics Letters 119: 302305.

Beladi, H. and R. Oladi (2011), "Does Trade Liberalization Increase Global Pollution?" Resource and Energy Economics 33: 172-178.

Benchekroun H. and N.V. Long (2012), "Collaborative Environmental Management: A Review of the Literature," International Game Theory Review 14(4).

Benitez, P.C., I. McCallum, M. Obersteiner, and Y. Yamagata (2007), "Global Potential for Carbon Sequestration: Geographical Distribution, Country Risk and Policy Implications," Ecological Economics 60: 572-583. 
Brock, W.A. and J.A. Scheinkman (1976), "Global Asymptotic Stability of Optimal Control Systems with Applications to the Theory of Economic Growth," Journal of Economic Theory 12(1): 164-190.

Caplan, A.J. (2006), "A Comparison of Emissions Taxes and Permit Markets for Controlling Correlated Externalities," Environmental and Resource Economics 34(4): 471-492.

Caplan, A.J. and E.C.D. Silva (2005), "An Efficient Mechanism to Control Correlated Externalities: Redistributive Transfers and the Coexistence of Regional and Global Pollution Permit Markets," Journal of Environmental Economics and Management 49(1): 68-82.

Caplan, A.J., R. Cornes, and E.C.D. Silva (2003) "An Ideal Kyoto Protocol: Emissions Trading, Redistributive Transfers and Global Participation," Oxford Economic Papers $55(2), 216-234$.

Conant, R.T. "Challenges and Opportunities for Carbon Sequestration in Grassland Systems: A Technical Report on Grassland Management and Climate Change Mitigation" Integrated Crop Management Volume 9 (FAO).

Cooper, R.N. (1998), "Toward a Real Global Warming Treaty," Foreign Affairs 77(2): 66-79.

De Zeeuw, A. (2008), "Dynamic Effects on the Stability of International Environmental Agreements," Journal of Environmental Economics and Management 55(2): 163-174.

Feng, H., C.L. Kling, and P.W. Gassman (2004), "Carbon Sequestration, Co-Benefits, and Conservation Programs," Choices Third Quarter (Fall).

Fudenberg, D. and D.K. Levine (1988) "Open-Loop and Closed-Loop Equilibria in Dynamic Games with Many Players," Journal of Economic Theory 44(1): 1-18.

Fudenberg, D. and J. Tirole (1991) Game Theory. MIT Press: Cambridge, MA.

Gore, A. J. (2007), "Moving Beyond Kyoto," The New York Times, 1 July. 
Kaplow, L. (2010), "Taxes, Permits, and Climate Change," NBER Working Paper No. 16268.

Keane, J., J. MacGregor, S. Page, L. Peskett and V. Thorstensen (2010), "Development, Trade and Carbon Reduction: Designing Coexistence to Promote Development," Overseas Development Institute Working Paper 315.

Long, Ngo Van. (1992), "Pollution Control: A Differential Game Approach," Annals of Operations Research 37(1): 283-296.

Long, N.V. (2010), A Survey of Dynamic Games in Economics. Surveys on Theories in Economics and Business Administration: Volume 1. World Scientific: London, England.

Long, N.V. (2015), "The Green Paradox in Open Economies: Lessons from Static and Dynamic Models," Review of Environmental Economics and Policies 9(2): 266-285.

Nordhaus, W. (2007), "The Challenge of Global Warming: Economic Models and Environmental Policy," Working Paper, Yale University.

Pavlova, Y. and A. De Zeeuw (2013), "Asymmetries in International Environmental Agreements," Environment and Development Economics 18(1): 51-68.

Pizer, W.A. (1997), "Prices vs. Quantities Revisited: The Case of Climate Change," Resources for the Future Discussion Paper 98-02.

Porter, M.E. (1990), The Competitive Advantage of Nations, New York, Free Press.

Porter, M.E. and C. Van der Linde (1995), "Toward a New Conception of the Environmentcompetitiveness Relationship," Journal of Economic Perspectives 9(4): 97-118.

Rose, A., B. Stevens, J. Edmonds, and M. Wise (1998), "International Equity and Differentiation in Global Warming Policy," Environment and Resource Economics 12(1): 25-51. 
Sohngen, B. and R. Sedjo (2004), "Carbon Sequestration in Global Forests. Resources for the Future, Washington, DC.

Stern Review (2007), The Economics of Climate Change: The Stern Review, Cambridge University Press.

United States Geological Survey (USGS) (2011), "Carbon Sequestration to Mitigate Climate Change." Retrieved from the internet on February 15, 2011 at http://pubs.usgs.gov/fs/2008/3097/pdf/CarbonFS.pdf.

van den Bijgaart, I. (2017), "The Unilateral Implementation of a Sustainable Growth Path with Directed Technical Change," European Economic Review 91: 305-327. 